\title{
Tradisi Adat Kawi'a Masyarakat Suku Moronene Di Kecamatan Poleang Utara Kabupaten Bombana
}

\author{
Anwar $^{1}$, Amal Arfan', Erman Syarif ${ }^{3}$ \\ ${ }^{123}$ Universitas Negeri Makassar \\ Email :
}

(Received: Agustus 2019; Reviewed: Agustus 2019; Accepted: September 2019; Published: September 2019)

Ini adalah artikel dengan akses terbuka dibawah license CC BY-NC-4.0 (C2019 oleh penulis (https://creativecommons.org/licenses/by-nc/4.0/ ).

\begin{abstract}
The study aims at (1) examining the proses of Kawi'a traditional tradition or marriage of Moronene tribe in North Poleang subdistrict in Bombana district, (2) the role of Tolea in Kawi'a traditional tradition of marriage of Moronene Tribe in North Poleang Subdsitrict in Bombana district, and (3) integrating the Kawia'a traditional tradition or marriage in Geography learning material in SMA (senior high school). This study employed qualitative research with ethnography approach. The data source of the study employed snowball sampling technique with the informants consisted of customary council chairman of Moronene, Tolea, and prominent people. Data Collecting technique employed direct observation, indepth interview, and documentation. Data analysis technique consisted of data collecting, data reduction, data display, and conclusion drawing. The results of the study reveal that (1) the process in Kawi'a tarditional tradition or marriage of Moronene tribe in North Poleang subdistrict in Bombana district is divided into three stages, namely pre-marriage stage which consist of Mowindahako (marriage proposal), Moduduhi, Mompokontodo (following the marriage proposal), Mesisiwi (persuading the bride), Mesampora (engagement), Lumanga (delivery the dowry) and Khatam Qur'an. The marriage stage consists of Melongko (picking up the bride), Metiwawa (taking the bride to the venue), Melawati/Moantani (welcoming the bride), Mompindai Sincu (confirming the bride and groom), pinokompe'olo (eating together in on plate), Pinokompompanga (eating the sirih pinang together) dan Montente Awu (Molulo together) and the Post-marriage is called Mohuletako Alo (taking the bride to the parent's in-law home); (2) the roles of Tolea in Kawi'a traditional tradition of marriage of Moronene Tribe in North Poleang Subdsitrict in Bombana district are the marriage proposal carrier, following the marriage proposal, discussing and deciding as well as taking the dowry and marriage cost, conducting the procession before and after the marriage and taking the bride to the parent's in-law home; (3) the Kawi'a traditional tradition or marriage of Moronene tribe can be integrated in Geography learning material in class XI at SMA inside or outside of the clas in a form of field observatioan and applying character education values caontained in Kawi'a traditional tradition such as being religious, discipline, responsibility and caring working togehter in daily lives in school environment as well as in the society.
\end{abstract}

Keywords: Merried; Tribe; Kawi'a; Prosesion 


\begin{abstract}
ABSTRAK
Tujuan Penelitian ini adalah (1) Untuk mengetahui proses dalam tradisi adat Kawi'a / perkawinan masyarakat Moronene di Kecamatan Poleang Utara Kabupaten Bombana, (2) Untuk mengetahui peran Tolea dalam adat tradisi Kawi'a / perkawinan masyarakat Suku Moronene di Kabupaten Bombana, (3) Untuk mengintegrasikan tradisi adat Kawi'a / Perkawinan dalam materi pembelajaran geografi di SMA. Penelitian ini menggunakan jenis penelitian kualitatif dengan pendekatan etnografi. Sumber data mengggunakan teknik snowball sampling dengan memilih informan yang terdiri dari Ketua Dewan Adat Moronene, Tolea dan Tokoh Masyarakat. Teknik pengumpulan data melalui observasi langsung, wawancara mendalam dan dokumentasi. Teknik analisis data terdiri dari pengumpulan data, reduksi data, display data dan penarikan kesimpulan. Hasil penelitian menunjukkan bahwa (1) proses dalam tradisi adat kawi'a / perkawinan masyarakat Moronene di Kecamatan Poleang Utara Kabupaten Bombana terbagi dalam tiga tahap yaitu tahap praperkawinan yang terdiri dari Mowindahako (Pelamaran), Moduduhi, Mompokontodo (Menyusul lamaran), Mesisiwi (membujuk Pengantin), Mesampora (Pertunangan), Lumanga (pengantaran Pokok Mahar) dan Khatam Qur'an. Tahap Perkawinan terdiri dari Melongko (Menjemput pengantin), Metiwawa (mengantar pengantin ke tempat acara), Melawati/Moantani (menyambut pengantin), Mompindai Sincu (Mengukuhkan Pengantin), pinokompe'olo (Makan Bersama dalam satu piring), Pinokompompanga (Makan Sirih Pinang Bersama) dan Montente Awu (Molulo Bersama) dan tahap Pascaperkawinan disebut Mohuletako Alo (mengantar Pengantin ke rumah orang tua laki-laki): (2) peran tolea dalam adat tradisi kawi'a I perkawinan masyarakat Suku Moronene di Kabupaten Bombana yaitu pembawa lamaran, menyusul lamaran, membicarakan dan memutuskan serta mengantar Pokok Mahar dan Biaya Perkawinan, melaksanakan prosesi adat sebelum dan sesudah perkawinan dan mengantar pengantin ke rumah orang tua pengantin lakilaki (3) tradisi adat Kawi'a / Perkawinan masyarakat suku moronene dapat dintegrasikan dalam materi pembelajaran geografi kelas XI (Sebelas) di SMA baik di dalam maupun di luar kelas dalam bentuk observasi lapangan dan menerapkan nilai-nilai pendidikan karakter yang ada dalam tradisi adat Kawi'a tersebut seperti Religius, Disiplin, Tanggung Jawab dan Peduli Sosial / Gotong Royong dalam kehidupan sehari-hari baik di lingkungan sekolah maupun di lingkungan masyarakat.
\end{abstract}

Kata Kunci: Pernikahan; Suku; Kawi'a; Prosesi

\section{PENDAHULUAN}

Menurut Ekblaw dan Mulkerne (Muhammad, 2012), Geografi Budaya merupakan ilmu pengetahuan yang mempelajari bumi dan kehidupannya, mempengaruhi pandangan hidup kita, makanan yang kita konsumsi, pakaian yang kita gunakan, rumah yang kita huni dan tempat rekreasi yang kita amati. Sedangkan, Geografi Budaya menurut Carl Sauer (Saleh, 2013) adalah ilmu pengetahuan yang menelaah sekitar tingkah laku manusia yang ditimbulkan karena adanya usaha adaptasi dan pemanfaatan lingkungan alam oleh manusia dalam usaha mempertahankan hidupnya.

Indonesia memiliki banyak pulau dan suku bangsa dengan corak kebudayaan yang beragam. Perbedaan letak geografis, keadaan alam dan latar belakang kebudayaan bukan menjadi halangan. Suatu kebudayaan dibentuk oleh kumpulan individu yang mempunyai latar belakang dan ciri khas sendiri sesuai dengan lingkungan tempat individu tersebut bertempat tinggal. Hasil karya yang diperoleh dari individu merupakan unsur-unsur kebudayaan dan masyarakat yang disatukan

Anwar dkk, Tradisi Adat Kawi'a Masyarakat Suku Moronene Di Kecamatan Poleang Utara Kabupaten Bombana 
oleh cita-cita dan pandangan hidup individu yang amat abstrak. Suatu cita-cita yang abstrak dapat mempengaruhi unsur dalam kehidupan kebudayaan dan menjadi pendorong unsur kebudayaan, serta sebagai pendorong banyak aktivitas dalam masyarakat (Hastuti \& Oswari 2016).

Tradisi suatu masyarakat merupakan bagian dari kebudayaan yang dapat memperkaya kebudayaan nasional. Hal ini sesuai dengan pasal 32 ayat 1 UUD Negara Republik Indonesia Tahun 1945, “ Negara memajukan kebudayaan nasional Indonesia di tengah peradaban dunia dengan menjamin kebebasan masyarakat dalammemelihara dan mengembangkan nilai-nilai budayanya“.

Menurut (Syarif \& Leo, 2019) dalam perspektif geografi budaya mencoba membandingkan distribusi perubahan dari area budaya dan distribusi dari kenampakan muka bumi dapat identifikasi karakteristik kenampakan lingkungan sebagai akibat dari pengaruh kebudayaan dan mengetahui peran tindakan manusia dalam penciptaan dan pemeliharaan kenampakan geografik

Suku Moronene merupakan salah satu suku yang ada di Sulawesi Tenggara dan berada di wilayah Kabupaten Bombana. Suku Moronene memiliki warisan kebudayaan yang unik dan beragam. Salah satu-nya adalah tradisi adat perkawinan yang dalam bahasa moronene disebut Kawi'a. Tradisi adat perkawinan merupakan upacara adat tradisional dan sakral, yang berarti bahwa upacara adat tradisional merupakan kelakuan atau tindakan simbolis manusia sehubungan dengan kepercayaan yang mempunyai maksud dan tujuan. Tradisi adat Kawi'a ini masih tetap di junjung tinggi dan dilaksanakan karena terikat dengan hukum-hukum adat yang wajib ditaati oleh segenap masyarakatnya dan juga merupakan salah satu pencerminan kepribadian atau penjelmaan dari pada suku Moronene itu sendiri dalam memperkaya budaya-budaya di Indonesia.

Perkawinan merupakan suatu peristiwa yang sangat penting dan harus mempersiapkan segala sesuatunya meliputi aspek fisik, mental, dan sosial ekonomi. Perkawinan yang baik adalah perkawinan yang sah dan tidak di bawah tangan, karena perkawinan adalah sakral dan tidak dapat dimanipulasikan dengan apapun. Perkawinan adalah suatu perjanjian yang suci, kuat, dan kokoh untuk hidup bersama secara sah antara seorang laki-laki dan perempuan membentuk keluarga yang kekal, santun menyantuni, kasih mengasihi, tentram dan bahagia $(\mathrm{Hj}$. Rahmatiah, 2016).

Perkawinan mempunyai tujuan yang agung dan motif yang mulia, karena perkawinan merupakan tempat persemian cinta, kasih sayang, untuk memperoleh keturunan yang sah dalam masyarakat serta hubungan timbal balik yang mesra antara suami dan istri (Santoso, 2016). Sejak zaman pra sejarah, perkawinan merupakan masalah yang penting karena perkawinan merupakan kebutuhan dasar (basic need) manusia. Setiap manusia memiliki naluri untuk mengembangkan keturunan dan kelangsungan hidupnya. Dalam hubungan inilah manusia melaksanakan perkawinan. Pada dasarnya selain untuk menyalurkan kebutuhan dasar manusia, perkawinan dilaksanakan dalam rangka mengembangkan keturunan dan melestarikan kehidupan manusia. Setiap manusia mempunyai naluri agar anak keturunannya dapat mewarisi dan meneruskan cita-cita hidupnya (Rohman, 2015).

Rumusan masalah dalam penelitian ini adalah sebagai berikut :

1. Bagaimana proses dalam tradisi adat kawi'a / perkawinan masyarakat Moronene di Kecamatan Poleang Utara Kabupaten Bombana?

2. Bagaimana peran tolea dalam tradisi adat kawi'a / perkawinan masyarakat Suku Moronene di Kecamatan Poleang Utara Kabupaten Bombana?

3. Bagaimana pengintegrasian nilai-nilai tradisi adat kawi'a / perkawinan masyarakat suku Moronene dalam pembelajaran Geografi di SMA?

Tujuan dalam penelitian ini adalah sebagai berikut :

1. Untuk mengetahui proses dalam tradisi adat kawi'a / perkawinan masyarakat Moronene di Kecamatan Poleang Utara Kabupaten Bombana?

2. Untuk mengetahui peran tolea dalam adat tradisi kawi'a / perkawinan masyarakat Suku Moronene di Kabupaten Bombana?

3. Untuk mengetahui pengintegrasian nilainilai tradisi adat Kawi'a / Perkawinan dalam pembelajaran geografi di SMA? 
Penelitian ini diharapkan dapat memberikan sumbangan pemikiran yang sebagai masukan atau literatur ilmiah yang dapat dijadikan sebagai bahan kajian khususnya dalam pengelolaan pariwisata alam.

\section{METODE}

Jenis penelitian yang digunakan dalam penelitian ini adalah penelitian deskriptif kualitatif dengan pendekatan etnografi.

Penelitian ini bertempat di Kecamatan Poleang Utara Kabupaten Bombana Sulawesi Tenggara. Alasan peneliti memilih lokasi tersebut, karena di Kecamatan Poleang Utara merupakan tempat tinggal Ketua Dewan Adat Moronene wilayah Poleang, Beberapa Tolea dan Tokoh Masyarakat

Penelitian ini berfokus pada :

1. Proses dalam tradisi adat kawi'a / perkawinan masyarakat Moronene di Kecamatan Poleang Utara Kabupaten Bombana

2. Peran tolea dalam tradisi adat kawi'a / perkawinan masyarakat Suku Moronene di Kecamatan Poleang Utara Kabupaten Bombana

3. Integrasi tradisi adat perkawinan masyarakat suku Moronene dalam pembelajaran geografi di SMA

Sumber data dalam penelitian ini bersumber dari hasil observasi langsung di lapangan serta hasil wawancara dengan informan yang dipilih dengan menggunakan teknik Snowball Sampling.

\section{HASIL DAN PEMBAHASAN}

\section{Hasil}

\section{Letak Geografis, Luas dan Batas Wilayah}

Secara astronomis, Kecamatan Poleang Utara terletak antara $4^{\circ} 35,32,7{ }^{\prime \prime}$ $4^{\circ} 48^{\prime}$ 14,0" Lintang Selatan, sertaantara $121^{\circ} 40^{\prime} 48^{\prime \prime}-121^{\circ} 53^{\prime} 17,9^{\prime \prime}$ BujurTimur.

Luas wilayah daratan Kecamatan Poleang Utara adalah 237, $27 \mathrm{Km} 2$ dan didominasi kawasan persawahan dan perkebunan seperti Nilam, Jambu Mente dan Coklat. Jarak ke Ibukota Kabupaten sekitar 28,5 Km, sedangkan jarak ke Ibukota Provinsi sekitar $187 \mathrm{Km}$.

Jumlah penduduk Kecamatan Poleang
Utara pada tahun 2018 sebanyak 13.158 jiwa, dengan jumlah laki-laki sebanyak 6.747 atau $51 \%$ dan jumlah perempuan sebanyak 6.411 atau $42 \%$ dengan kepadatan penduduk sebanyak 55 orang per $\mathrm{Km} 2$.

\section{Proses dalam Tradisi Adat Kawi'a / Perkawinan Masyarakat Suku Moronene di Poleang Kabupaten Bombana Sulawesi Tenggara}

a. Tahap Praperkawinan

Tahap praperkawinan merupakan tahap awal yang dilakukan sebelum acara perkawinan, rangkaian acara dalam tahap ini adalah sebagai berikut :

1) Mowindahako

Mowindahako artinya meminang. Mowindahako dilakukan dengan cara orang tua laki-laki akan meminta bantuan seorang Tolea yang dianggap mampu mewakili maksud dan tujuan keluarga laki-laki untuk menyampaikan lamaran kepada orang

\section{2) Moduduhi}

Moduduhi merupakan bentuk pernyataan orang tua laki-laki mengenai kesanggupan hati dalam menerima atau mendapatkan jawaban mengenai lamaran yang diberikan oleh orang tua perempuan pada lamaran sebelumnya.

3) Mompokontodo

Mompokontodo artinya menetapkan lamaran pihak laki-laki dengan maksud memperoleh jawaban dari orangtua pihak perempuan.

\section{4) Mesampora}

Mesampora merupakan salah satu tradisi yang cukup unik dalam perkawinan suku Moronene. Tradisi Mesampora merupakan sebuah bentuk pengabdian seorang laki-laki kepada orangtua perempuan yang dilamar dengan membantu pekerjaan orangtua perempuan.

5) Mesisiwi

Mesisiwi merupakan prosesi membicarakan pokok mahar dan biaya perkawinan yang akan dibebankan kepada laki-laki dan kapan waktu yang tepat untuk datang mengantar pokok mahar tersebut dan juga membujuk atau meminta kesediaan hati calon mempelai perempuan untuk menerima lamaran dari orangtua laki-laki.

6) Lumanga / Montompa Langa

Setelah tiba hari yang telah ditentukan 
maka akan dilanjutkan dengan prosesi pengantaran dan penyerahan pokok mahar atau benda adat dan biaya perkawinan yang disebut dengan Lumanga. Lumanga atau sering juga disebut dengan Montompa Langa merupakan acara penaikan atau pengantaran pokok mahar dan biaya perkawinan yang dilakukan oleh orangtua calon pengantin lakilaki ke rumah orangtua calon pengantin perempuan.

7) Khatam Al-Qur'an

Acara khatam Al-Qur'an dilakukan sebagai bentuk rasa syukur kepada Allah SWT sebagai Tuhan yang Maha Esa dan serta sanjungan dan shalawat kepada Nabi Muhammad SAW yang dirangkaikan dengan acara barzanji.

\section{b. Tahap Perkawinan}

Tahap perkawinan masyarakat suku Moronene memiliki beberapa rangkaian acara yang secara berurutan. Kegiatan yang dimaksud antara lain sebagai berikut :

1) Melongko

Melongko artinya mengundang dan menjemput pengantin perempuan untuk datang ke tempat acara setelah pengantin lakilaki melakukan prosesi Mooli Laica. Mooli Laica terdiri dari dua kata yaitu Mooli (Membeli) dan Laica (Rumah) adalah suatu prosesi dimana pengantin laki-laki membeli rumah yang ditempati pengantin perempuan. Setelah proses Mooli Laica selesai pengantin perempuan akan

2) Metiwawa

Metiwawa artinya mengantar pengantin perempuan beserta rombongan untuk datang ke rumah atau tempat diadakannya acara. Pengantin perempuan akan diantar menggunakan tandu dan diiringi dengan Tua Mentaa dan Tarian Mo

3) Melawa Hai'i Patande / Moantani

Melawa Hai'i Patande / Moantani adalah proses penyambutan dengan mempersilahkan pengantin perempuan untuk istirahat di tempat persitirahatan yang disebut Patande atau pendopo setelah pengantin perempuan beserta keluarga tiba di tempat acara.

4) Mompindai Sincu

Mompindai sincu merupakan pengukuhan kedua mempelai untuk memasuki rumah tangga yang baru dan juga untuk mempersatukan keluarga dari kedua belah pihak dengan cara mencuci kaki kedua mempelai pada sebuah wadah dari pelepah pohon pinang yang disebut Sincu. Wadah Sincu tersebut diisikan dengan air, kapak, daun kumapu, daun olondoro dan daun doule.

5) Pinokompe'olo

Pinokompe'olo dilakukan setelah acara akad nikah selesai. Pinokompe'olo adalah prosesi adat mempersatukan kedua mempelai dengan cara makan bersama dalam satu piring yang melambangkan bahwa kelak dua insan ini akan tinggal bersama dalam satu rumah, satu tubuh, satu tulang, satu darah dan satu rahasia. 6) Pinokompompanga

Pinokompompanga merupakan prosesi adat yang dilakukan oleh kedua pengantin dengan dituntun untuk makan sirih pinang bersama. Daun sirih dan pinang adalah salah satu syarat yang harus ada dalam ritual adat perkawinan suku Moronene, sebagai pelengkap sahnya ritual tersebut. Dengan makan sirih (Bite) dan buah pinang (Wua), akan menghasilkan warna merah yang mengandung makna bahwa kedua mempelai bertekad untuk bersatu dalam kebersamaan.

\section{7) Montente Awu}

Sebagai acara penutup dari seluruh rangkaian prosesi adat dalam tahap perkawinan ini, kedua pengantin bersama dengan orang tua, keluarga dan tokoh adat akan melakukan prosesi Montente Awu yang artinya Molulo / Menari Lulo Bersama dengan makna sebagai bentuk rasa syukur kepada Tuhan Yang Maha Esa atas terlaksananya acara ini.

\section{c. Tahap Pascaperkawinan}

Tahap pascaperkawinan disebut Mohuletako Alo. Mohuletako Alo artinya mengantar kedua pengantin ke rumah orang tua pengantin lakilaki setelah acara pernikahan berlangsung dengan waktu yang sudah disepakati sebelumnya oleh kedua keluarga. Tradisi ini dilakukan dua atau empat hari pasca perkawinan yang diistilahkan dengan Oleo Ongkunda (hari pendek) waktunya sekitar dua hari setelah Perkaw dan Oleo Mentaa (Hari Panjang) waktunya sekitar empat hari setelah pernikahan tergantung dari kesepakatan kedua belah pihak. Biasanya tradisi ini dilaksanakan karena pihak orang tua laki-laki juga ingin mengadakan acara di tempat tinggal mereka. 
3. Peranan Tolea dalam Tradisi Adat Kawi'a / Perkawinan Masyarakat Suku Moronene di Poleang Utara Kabupaten Bombana

Kehadiran Tolea dalam sebuah perkawinan merupakan hal yang sangat penting, karena Tolea merupakan orang yang mengatur jalannya prosesi prosesi adat dalam perkawinan masyarakat Moronene di Kabupaten Bombana khususnya di Kecamatan Poleang Utara mulai dari prosesi pelamaran sampai prosesi terakhir dalam acara tersebut hampir semua dilkasanakan oleh Tolea.

Tugas pertama seorang Tolea adalah membawa lamaran. Pada acara lamaran orang tua dari pihak laki-laki akan datang kepada Tolea menyampaikan maksud dan tujuannya dalam hal ini tentang lamaran, dan dimintai kesediannya untuk membawa lamaran sebagai perwakilan dari keluarga laki-laki.

Tugas Tolea yang kedua adalah menyusul lamaran. Lamaran yang telah dihantarkan sebelumnya tidak langsung ditolak atau diterima tetapi akan dimintai jawaban setelah beberapa hari berikutnya, hal ini dilakukan agar orang tua pihak perempuan memiliki waktu yang cukup untuk mempertimbangkan atau membicarakan lamaran tersebut kepada anak perempuannya dan seluruh keluarga sehingga Tolea datang kembali untuk membicarakan lebih lanjut tentang prosesi lamaran. Tolea akan meminta kepastian lamaran dan memantapkan lamaran tersebut apabila lamaran betul-betul diterima. Apabila lamaran diterima, tolea akan meminta, kapan waktu yang tepat untuk datang kembali membicarakan dan memutuskan pokok mahar dan biaya perkawinan.

Tugas Tolea yang ketiga adalah membicarakan, memutuskan serta mengantar pokok adat dan biaya perkawinan.

Sebagai pelaksana prosesi adat tugas Tolea memang tidak mudah karena dalam prosesi adat ini, semua diatur dan dijalankan oleh Tolea sebagai perwakilan adat Mulai dari acara Melongko (menjemput pengantin), Metiwawa (mengantar Pengantin), Melakukan Proses Melawa Hai'i Patande (Penyambutan), Mompindai Sincu (Pengukuhan Pengantin), Pinokompompe'olo (Makan Bersama), Pinokompompanga (Makan Sirih Pinang), dan
Montente Awu (Molulo Bersama), semua dipandu oleh Tolea sampai acara selesai.

Sebagai tugas terakhir, Tolea akan mengantar kedua pengantin ke rumah orang tua pengantin laki-laki, yang sebelumnya telah dilakukan kesepakatan bersama tentang waktu yang akan diambil untuk mengantar kedua pengantin ke rumah orang tua pengantin lakilaki, apakah dua hari atau empat hari setelah acara perkawinan selesai

\section{Integrasi Nilai-Nilai Tradisi Adat} Kawi'a / Perkawinan Masyarakat Moronene di Kabupaten Bombana dalam Pembelajaran Geografi di SMA. Kebudayaan tidak dapat dipisahkan dengan pendidikan, karena untuk menjaga dan melestarikan budaya itu sendiri, cara efektif untuk mentransfer budaya salah satunya melalui pendidikan. Kebudayaan dan pendidikan memiliki hubungan yang sangat erat karena saling melengkapi dan mendukung antar satu sama lain. Pendidikan sendiri bertujuan untuk selalu melestarikan dan selalu meningkatkan kebudayaan itu sendiri. Kebudayaan juga berhubungan erat dengan mata pelajaran Geografi.

Tradisi adat Kawi'a / Perkawinan Masyarakat Suku Moronene di Kecamatan Poleang Utara dapat diintegrasikan dalam pembelajaran Geografi SMA di kelas XI (Sebelas). Metode yang dapat digunakan oleh terkait materi kebudayaan, salah satunya adalah pembelajaran di dalam dan di luar kelas dengan pendekatan Contextual Teaching and Learning (CTL) dan juga mengintegrasikan nilai-nilai pendidikan karakter yang terdapat dalam tradisi tersebut ke dalam pembelajaran di sekolah seperti Religius, Disiplin, Tanggung Jawab dan Peduli Sosial / Gotong Royong.

\section{Pembahasan}

1. Proses dalam Tradisi Adat Kawi' a / Perkawinan Masyarakat Suku Moronene di Kecamatan Poleang Utara Kabupaten Bombana

Berdasarkan hasil temuan keterangan yang diperoleh dari informan dan data yang didapatkan di lapangan, diketahui bahwa tradisi adat Kawi'a / perkawinan masyarakat suku Moronene di Kecamatan Poleang Utara Kabupaten Bombana terbagi dalam tiga tahap 
yaitu tahap praperkawinan yang terdiri atas tahap Mowindahako, Monduduhi, Mompokontodo, Mesampora, Mesisiwi, Lumanga/Montompa Langa dan Khatam AlQur'an. Tahap perkawinan terdiri atas tahap Melongko, Metiwawa, Melawa Hai'i Patande I Moantani, Mompindai Sincu, Pinokompe'olo, Pinokompompanga dan Montente Awu. tahap pascaperkawinan disebut tahap Mohuletako Alo. Hal ini sejalan dengan apa yang dikemukakan oleh depdikbud (1994), bahwa upacara perkawinan dapat berupa upacara pelaksanaan praperkawinan, perkawinan dan tahap upacara setelah perkawinan. Hal ini disampaikan pula oleh Satriana (2015) bahwa Penyelenggaraan perkawinan senantiasa disertai dengan berbagai upacara yang kesemuanya itu bertujuan untuk menjamin terpenuhinya semua kepentingan yang bersangkutan.

\section{Peranan Tolea dalam Tradisi Adat Kawi'a / Pernikahan Masyarakat Suku Moronene di Kecamatan Poleang Utara Kabupaten Bombana}

Berdasarkan hasil wawancara yang didapat dari Informan bahwa peranan tolea dalam tradisi adat perkawinan masyarakat suku Moronene adalah sebagai pembawa lamaran dalam proses Mowindahako, menyusul lamaran, membicarakan dan memutuskan mahar, mengantar pokok mahar dan biaya perkawinan, pelaksana ritual Mombula Tula dan Mekoloi'i (Metompa Tua Mentaa), pelaksana prosesi adat sebelum dan sesudah akad nikah, dan mengantar pengantin ke rumah orangtua pengantin laki-laki sesuai dengan waktu yang telah ditentukan. Hal ini seperti yang dikatakan oleh Yasmud (2011) dalam penelitiannya bahwa Tolea adalah tokoh yang paling besar peranannya sebagai juru bicara adat, posisi Tolea berada pada pihak mempelai laki-laki sebagai duta yang menyampaikan segala ihwal pokok adat. Sebagian besar adat perkawinan yang dilaksanakan di wilayah Sulawesi Tenggara memang identik dan menjadi ciri khas dengan keberadaan tokoh adat (Tolea) sebagai perantara antara keluarga mempelai laki-laki dan mempelai perempuan sejak proses pelamaran hingga setelah proses akad nikah dilaksanakan.

\section{Integrasi Nilai-Nilai Tradisi Adat Kawi'a / Perkawinan Masyarakat Moronene di Kecamatan Poleang Utara Kabupaten Bombana dalam Pembelajaran Geografi di SMA}

Berdasarkan hasil temuan di lapangan Tradisi adat Kawi'a / Perkawinan Masyarakat Suku Moronene dapat diintegrasikan dalam pembelajaran Geografi SMA melalui pembelajaran di dalam dan di luar kelas dengan pendekatan Contextual Teaching and Learning (CTL) serta mengintegrasikan nilainilai pendidikan karekter yang terdapat dalam tradisi tersebut ke dalam pembelajaran di lingkungan sekolah seperti Religius, Disiplin, Tanggung Jawab dan Peduli Sosial / Gotong Royong.

\section{SIMPULAN DAN SARAN}

\section{Simpulan}

Berdasarkan analisis hasil wawancara, observasi dan dokumentasi tentang Tradisi Adat Kawi'a Perkawinan Masyarakat suku Moronene di Kecamatan Poleang Utara Kabupaten Bombana, maka penulis dapat menarik kesimpulan sebagai berikut

1. TradisiAdatKawi'a perkawinan masyarakat suku Moronene di Kabupaten Bombana khususnya di Kecamatan Poleang Utara terdiri dari tiga tahap yaitu tahap praperkawinan yang terdiri dari prosesiMowindahako,

Mompokontodo, Mesisiwi, Mesampora, Lumanga, Khatam AlQur'an. Tahap Perkawinan terdiri dari proses Melongko, Metiwawa, Mompindai Sincu, Pinokompe'olo, Pinokompompanga, MontenteAwu. Dan tahap Pascaperkawinan yang disebut dengan Mohuletako Alo.

2. Peranan Tolea dalam tradisi adat kawi'a / Perkawinan masyarakat suku Moronene di Kecamatan Poleang Utara Kabupaten Bombana adalah sebagai Pembawa Lamaran, Menyusul Lamaran, Membicarakan. Memutuskan, Mengantar Pokok Adat 
dan Biaya Perkawinan, Melaksanakan Prosesi Adat Sebelum dan Sesudah Prosesi Akad Nikah, Mengantar pengantin ke Rumah Orangtua pengantin Laki-Laki.

3. Tradisi Adat Kawi'a / perkawinan masyarakat suku Moronene di Kabupaten Bombana dapat dimanfaatkan menjadi sumber belajar dan diintegrasikan ke dalam mata pelajaran Geografi dengan pendekatan CTL (Contextual Teaching and Learning), nilai-nilai pendidikan karakter yang dapat dilihat dalam tradisi adat Kawi'a terdiri dari religius, disiplin, tanggung jawab dan peduli sosial / gotong royong .

\section{Saran} adalah :

Adapun saran dalam penelitian ini

1. Untuk masyarakat Suku Moronene Kabupaten Bombana disarankan untuk melaksanakan rentetan adat perkawinan agar nilai-nilai adat tetap dipertahankan.

2. Mengikut sertakan kaum muda dalam proses adat istiadat, sehingga generasi muda dapat mempersiapkan diri untuk menjadi bagian dari pelaksanaan adat.

3. Dalam proses pembelajaran Geografi khususnya dalam materi kebudayaan, peserta didik diperkenalkan langsung dengan sumber belajarnya untuk meningkatkan pemahaman dan menumbuhkan rasa cinta terhadap kebudayaannya sendiri.

\section{DAFTAR RUJUKAN}

Departemen Pendidikan dan Kebudayaan. 1994/1995. Adat dan Upacara Perkawinan Daerah Bengkulu.

Hastuti, Erni \& Oswari, T. 2016. Budaya Pernikahan Masyarakat Minang Rantau. Jurnal UG, 10 (8), 1-11. Universitas Gunadarma Jakarta.

Hj. Rahmatiah HL. 2016. Studi Kasus Perkawinan di Bawah Umur. Jurnal Al-
Daulah, 5 (1), 144 - 166. Fakultas Syariah dan Hukum Universitas Islam Negeri (UIN) Alauddin Makassar

Muhammad, Janu. 2012. Pengertian Geografi Budaya.

http://1janumuhammad.wordpress.com/ 2012/12/30/pengertian-geografi-

budaya/. Diakses tanggal 3 Maret 2019.

Rohman, Fatkhur. 2015. Makna Filosofi

Tradisi Upacara Perkawinan Adat Jawa

Kraton Surakarta dan Yogjakarta.

Skripsi. Tidak dipublikasikan.

Semarang : Fakultas Ushuluddin UIN Walisongo.

Saleh, Hadwin. 2013. Geografi Budaya dan

Identitas Regional.

Hadwinsaleh.blogspot.com/2013/01/ge ografi-budaya-dan-identitas-

regional.html. diakses tanggal 1 maret 2019.

Santoso. 2016. Hakekat Perkawinan Menurut Undang-Undang Perkawinan, Hukum

Islam Dan Hukum Adat. Jurnal

Pemikiran dan Penelitian Sosial

Keagamaan, 7 (2), 412 - 434.

Satirana, Eka. 2015. Makna Ungkapan Pada Upacara Perkawinan adat Bulukumba di Desa Buhung Bundang Kecamatan Bontotiro Kabupaten Bulukumba. Jurnal Humanika, 3 (15).

Syarif, E., \& Leo, M. N. Z. (2019). Persepsi Masyarakat tentang Tradisi A'lammang di Desa Lantang, Kecamatan Polombangkeng Selatan, Kabupaten Takalar. LaGeografia, 18(1), 1-8.

Yasmud. 2011. Tradisi Lisan Mowindahako Suku Tolaki di Sulawesi Tenggara. Tesis tidak diterbitkan. Depok. Pascasarjana Universitas Indonesia.

\section{Editor In Chief}

Rosmini Maru

rosminimaru@unm.ac.id

\section{Publisher}

Geography Education, Postgraduate Program, Universitas Negeri Makassar $\mathrm{Jl}$. Bonto Langkasa Gunungsari Baru Makassar, 90222 Kampus PPS UNM Makassar Gedung AB ruang 01 , Indonesia Email : ugj@unm.ac.id Info Berlangganan Jurnal 085299874629 / Ihsan 